\title{
JOURNAL.RU
}

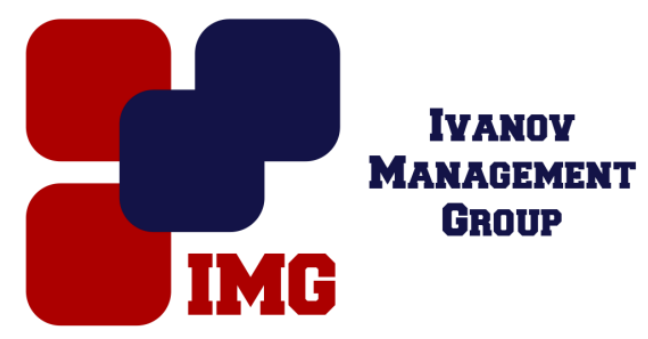

Сирая Г.С.

Южный Федеральный Университет

Таганрог, Россия

doi: $10.18411 / 1 \mathrm{j}-31-05-2017-67$

idsp 000001:1j-31-05-2017-67

\section{Сущностно-содержательные особенности понятия «Управление качеством»}

\begin{abstract}
Аннотация
Статья посвящена системному исследованию сущности и содержания понятия «Управление качеством». Определены понятия «качество», «обеспечение качества», «управление качеством», «система качества», «система менеджмента качества», а также рассмотрен механизм управления качеством на предприятии в рамках функционирования системы менеджмента качества.
\end{abstract}

Ключевые слова: качество, управление качеством, обеспечение качества, система качества, система менеджмента качества, механизм управления качеством

\section{Abstract}

Article is devoted to a system research of essence and the maintenance of the concepts "quality", "ensuring quality", "quality management", "quality system", "quality management system" are defined, and also the quality management mechanism at the enterprise within functioning of a quality management system is considered.

Key words: quality, quality management, ensuring quality, quality system, quality management system, quality management mechanism

В современных рыночных условиях конкурентоспособность предприятия зависит от соотношения двух показателей: цена продукции и качество продукции. В настоящее время именно качественная продукция может привлечь потребителя и, соответственно, обеспечить конкурентоспособность 
предприятия. В связи с этим понятие «управление качеством» получило широкое распространение.

Изучение понятия «управление качеством», его сущности и содержания необходимо начать с трактовки термина «качество». Исследования сущности понятия «качество» проводятся с точки зрения философии, социологии, экономики, а также технической и других позиций [1]. Для производственного предприятия термин «качество», прежде всего, связан с разработкой, производством и эксплуатацией продукции, т.е. основными этапами создания и использования продукции. Следовательно, с позиции экономики и управления предприятием объектом «качества», прежде всего, является качество продукции и услуг.

Согласно международному стандарту ИСО 9000 качество - это степень соответствия совокупности присущих характеристик объекта требованиям, где объект может быть материальным, нематериальным и воображаемым, а требование - это потребность или ожидания, которое установлено, обычно предполагается или является обязательным [8].

Исходя из данной формулировки, объектом качества может быть:

- продукция - результат деятельности предприятия, выраженный в вещественной (изделие, материал и т.п.), невещественной форме (выполнение работ и услуг);

- деятельность или процесс - совокупность взаимосвязанных и (или) взаимодействующих видов деятельности, использующих входы для получения намеченного результата [8];

- предприятие, подразделения предприятия или отдельное лицо, а также их будущее положение (воображаемая форма объекта);

- различные комбинации из них.

«Присущие» характеристики объекта означают, что они не могут быть присвоены объекту, а должны быть в него заложены в процессе его создания (разработки, производства) и оценены при его эксплуатации.

В современной литературе по вопросам управления качеством [6, 7] понятие «качество» трактуют как комплексное понятие, характеризующее все стороны деятельности предприятия и включающее в себя четыре составляющих:

- всеобщее качество - обеспечение высокого организационнотехнического уровня производства в целом; 
- качество фирмы - качество руководства и управления предприятием;

- качество работы - качество работы, непосредственно связанной с выпуском продукции;

- качество продукции.

Bce эти четыре составляющих представляют в виде пирамиды, в основании которой находится качество продукции, на вершине - всеобщее качество. При этом, качество продукции является результатом обеспечения качества работы, качества фирмы и качества предприятия в целом - всеобщего качества.

Аналогичную позицию излагает В.Я. Цветков [5], представляя качество, как четыре дополняющих друг друга компонента: соответствие техническим условиям; конкурентоспособность продукции; системное качество конструкции; соответствие требованиям потребителя. Следовательно, качество - комплексное понятие, характеризующее эффективность всех сторон предпринимательской деятельности.

Таким образом, в настоящее время понятие «качество» необходимо рассматривать в комплексе и не сводить только к одной составляющей.

Такая трактовка понятия «качества» сформировалась в ходе развития теории управления качеством под воздействием историко-производственных обстоятельств [2]. C развитием производства изменялись объективные требования к качеству продукции, а само понятие «качество» постоянно расширялось и уточнялось.

С начала и до середины 60-х годов XX века при становлении крупного промышленного производства под «качеством» понималось отсутствие дефектов и соответствие продукции стандарту. Поэтому для получения качественной продукции появился цеховой контроль качества, который был основан на принципах Ф.Тейлора и заключался в обнаружении дефекта и изъятии бракованного изделия из процесса производства как можно раньше. Данная модель управления качеством получила название традиционная концепция управления качеством.

Развитие массового производства, увеличение объемов выпуска, повышение сложности изделий стали предпосылками для появления статистического контроля качества. Под качеством стали понимать не только соответствие изделия требованиям, но и стабильность процессов производства. Предупреждение выпуска некачественной продукции стали осуществлять путем 
контроля процесса производства и выявления причин появления дефектов с помощью методов математической статистики. Основоположниками теории статистического управления качеством стали американские ученые У.А.Шухарт и Дж.М.Джуран.

В 60-х годах XX века американским ученым А. В. Фейгенбаумом была разработана концепция комплексного управления качеством. В основе этой концепции - обеспечение качества на всех стадиях создания продукции. Объектом понятия «качество» теперь выступала не только готовая продукция, но и каждый этап в процессе ее создания. А. В. Фейгенбаум ввел понятие «обратная связь», через которую информация о несоответствии качества заданным требованиям поступает в специальное подразделение для проведения анализа его возникновения и разработке мер по устранению. Таким образом, появилась возможность говорить об управлении качеством.

На основе теории комплексного управления качеством А. В. Фейгенбаума в разных странах в 60-х - 70-х годах XX века были разработаны различные концепции управления качеством с учетом национальных и экономических условий.

В Японии была разработана и внедрена концепция CWQC (Управление качеством в рамках всей компании) - всеобщее участие в управлении качеством всех работников предприятия, непрерывное обучение в области обеспечения качества, широкое внедрение статистических методов контроля качества. Автором этой концепции был японский ученый К. Исикава.

В нашей стране в период формирования комплексного подхода к управлению качеством были созданы различные системы качества [4]. Так, в 50х годах была разработана и внедрена система качества КАНАРСПИ (качество, надежность, ресурс с первых изделий) - выявление на этапе проектирования максимального количества причин отказов и их устранение в допроизводственый период; в 70-х годах - комплексная система управления качеством продукции (КС УКП) - воплощение идеи комплексного управления качеством на основе стандартизации.

В конце 80-х годов XX века была сформирована методология управления качеством на основе международных стандартов серии ИСО 9000. Стандарты этой серии ввели такие понятия, как «обеспечение качества», «управление качеством», «система качества», «система менеджмента качества» и установили общие требования для различных предприятий и организаций к разработке, внедрению и функционированию систем менеджмента качества. Понятие 
«качество» стало включать в себя не только соответствие качества продукции требованиям заказчика, а также гарантию качества - предоставление заказчику доказательств того, что разработанная, внедренная и функционирующая на предприятии система менеджмента качества соответствует современным условиям и позволяет выпускать качественную продукции. Возникло самостоятельное направление менеджмента - менеджмент качества.

Современная версия ИСО 9000 [8] определяет менеджмент качества, как скоординированную деятельность по руководству и управлению организацией применительно к качеству, которая включает в себя:

- планирование качества - установление политики и целей в области качества, разработка процессов для достижения этих целей и определение необходимых ресурсов;

- обеспечение качества - создание уверенности, что требования к качеству будут выполнены;

- управление качеством - выполнение требований к качеству;

- улучшение качества - повышение способности выполнить требования к качеству.

Таким образом, в современной терминологии термин «управление качеством» в узком понимании - это часть менеджмента качества, представляющая собой деятельность, направленную на достижение соответствия продукции требованиям потребителя. Однако, в широком смысле понятие «управление качеством» включает в себя понятие «качество» в комплексном его понимании, а также понятие «управление». В общем виде управление - целенаправленный перевод любой заданной системы в нужное состояние и поддержание режима ее деятельности до получения требуемого результата. Следовательно, понятие «управление качеством» неразрывно связано с понятиями «система», «система качества», «система менеджмента качества». Согласно [8]:

- система - совокупность взаимосвязанных и (или) взаимодействующих элементов;

- система качества - совокупность взаимосвязанных методов, форм и средств, предназначенных для обеспечения качества;

- система менеджмента качества - совокупность взаимосвязанных или взаимодействующих элементов организации для разработки 
политики и целей в области качества, а также процессов для достижения этих целей.

Следовательно, система менеджмента качества представляет собой совокупность подразделений и должностных лиц предприятия (управленческих органов и объектов управления), мероприятий, методов и средств, направленных на установление, обеспечение и поддержание качества продукции.

Система менеджмента качества разрабатывается с учетом организационной структуры управления предприятием и жизненного цикла выпускаемой продукции, включающего все этапы жизни изделия: маркетинг, разработка, материально-техническое снабжение, технологическая подготовка производства, производство, контроль и испытания продукции, упаковка и хранение, реализация и распределение продукции, эксплуатация, техническое обслуживание, утилизация.

Таким образом, «управление качеством» включает в себя сложный механизм управления качеством продукции в рамках функционирования системы менеджмента качества. В общем виде механизм управления качеством продукции можно представить как систему, состоящую из ряда общих, специальных и обеспечивающих подсистем (рисунок 1).

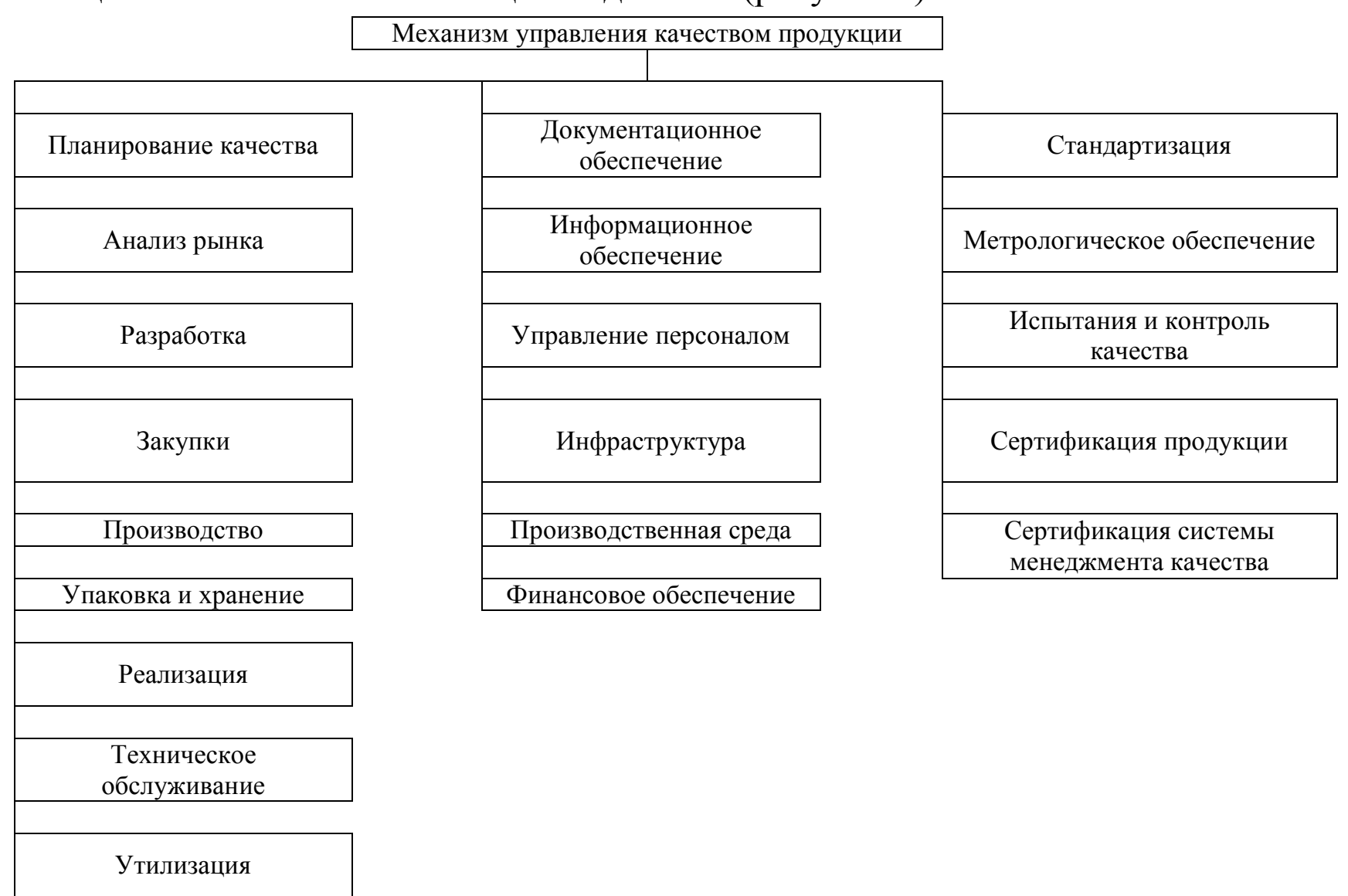


К общим подсистемам относится планирование качества, a также выполнение процессов жизненного цикла продукции: анализ рынка и установление требований к продукции (маркетинг), разработка, закупки (материально-техническое снабжение), производство, упаковка и хранение готовой продукции, реализация продукции, техническое обслуживание, утилизация.

Обеспечивающие подсистемы механизма управления качеством включают в себя документационное обеспечение (обеспечение законодательными и нормативными документами, регламентами по выполнению процессов); управление персоналом (подбор, обучение и мотивация персонала); информационное обеспечение (ведение баз данных, использование программного обеспечения); обеспечение инфраструктурой (здания, помещения, оборудование и т.п.); обеспечение производственной средой (создание необходимых условий окружающей среды); финансовое обеспечение.

К специальным подсистемам относятся стандартизация; метрологическое обеспечение; испытания и контроль качества продукции и процессов ее изготовления; сертификация продукции и системы менеджмента качества.

Представленный механизм управления качеством основан на принципах общего менеджмента. Этап планирования включает в себя анализ рынка, установление требований к продукции, определение планов обеспечения качества. Этап оперативного управления состоит из организации, координации, регулирования и мотивации. Специфическими системами в управлении качеством являются стандартизация и сертификация.

Таким образом, управление качеством - одна из фундаментальных категорий. С историей развития производства развивалась и теория управления качеством. Расширялось и уточнялось само понятие «качество» от соответствия конкретным требованиям, до комплексного понятия, характеризующего деятельность предприятия в целом и отражающее удовлетворение потребностей заказчика и общества в целом. Появилось понятие «управление качеством» и, как объект управления, - понятие «система качества». В настоящее время под понятием «управление качеством» понимается отдельное направление менеджмента. При этом, для качества, как объекта менеджмента характерны все составляющие менеджмента: планирование, обеспечение, руководство (управление), контроль и улучшение. 
1. Гладилина И.П., Колесник В.В. Сущность и содержание научной категории «качество» // Фундаментальные исследования - 2015 № 9-3. - С. 541-544.

2. Горбашко Е.А. Управление качеством: Учебное пособие / Е.А. Горбашко, Ю.А. Рыкова, Л.Е. Скрипко. - СПб.: Изд-во СПбГЭУ, 2016. - 126 с.

3. Евстропов Н.А. Менеджмент качества предприятий и организаций [Электронный ресурс]: Учебное пособие / Н.А. Евстропов, В.М. Корнеева, С.В. Бабыкин Электронные текстовые данные. М.: Академия стандартизации, метрологии и сертификации, 2013. - 216 с. - Режим доступа: http://www.iprbooksshop.ru /44346.html. - ЭБС "Iprbooks"

4. Летучев Г.М., Васильев В.А., Александрова С.В. Управление качеством на современном предприятии // Сборник: Управление качеством Избранные научные труды Пятнадцатой международной научно-практической конференции - 2016 - С. 211-214.

5. Цветков В.Я. Эволюция управления качеством // Образовательные ресурсы и технологии - 2017 № 1(18). - С. 64-71.

6. Шевчук Д.А. Управление качеством: Учебник/ Д.А. Шевчук. - М.: ГроссМедиа РОСБУХ, 2008. - 216 с.

7. Щурин К.В., Воробьев В.Л., Косых Д.А. Управление качеством в историкофилософском аспекте: Учебное пособие / К.В. Щурин. - Оренбург: Изд-во ОГУ, 2013. $-232 \mathrm{c}$.

8. ГОСТ Р ИСО 9001-2015 Системы менеджмента качества. Требования. 